\title{
MODERN EQUIPMENT TRANSPORT SOLUTIONS FOR STREAMLINING DELIVERIES WITHIN THE FRAMEWORK OF “THE LAST MILE LOGISTICS"
}

\begin{abstract}
"The last mile", although it is the final but also extremely important and generating a considerable challenge element of the supply chain. As a result, for transport operators, transport on the last part of road, to the door of each end customer, is sometimes the most expensive and the most problematic. Therefore, without the implementation of new solutions and vehicles, it will not be possible to increase efficiency in completing tasks - i.e. the increase in the number of successfully completed deliveries required by the market, while limiting the cost and time of each single delivery. The article is based on the analysis of the latest scientific and primary commercial studies devoted to this issue, supplemented with own conclusions and observations of the author.
\end{abstract}

Keywords: transport, last mile logistics

\section{Introduction}

The term "last mile logistics" refers to a phenomenon that in the organization itself and the implementation of shipments is not anything new. However, recently, it has definitely gained in importance due to changes in the transport and logistics systems for the distribution of goods on the usually final sections of the process.

The last mile logistics can be defined as a set of related organizational activities in the areas of transport and logistics, regarding delivery at the last part of road, and precisely delivery of shipments to end customers. Although this segment is the shortest in the entire displacement chain, but because of the scale of challenges and problems associated with it, it often turns out to be the most expensive and the most difficult in real execution. Of course, it must be emphasized that 
the term "last mile" is used only for illustrative purposes, as it does not only concern only the "last mile", but the entire last part. This is often replaced by the equivalent term "last kilometer". These expressions can therefore be used fully interchangeably, but the first of them has gained much more popularity and is therefore often used.

The problem of deliveries under the so-called last mile logistics concerns mainly actual contractors-operators of these deliveries. They are usually suppliers of letters, parcels and courier parcels, seller of mail and food suppliers on the phone. The last part of the road - to the door/to the door of end customers, due to the size of the challenges standing here, requires the implementation of a number of optimization solutions, which do not have to be implemented on such a scale on earlier stages. These challenges are a derivative of changes in the market for purchases of goods and services and related changes in consumer behavior and expectations.

The purpose of this article is to indicate new equipment and vehicle solutions, in conjunction with changes simultaneously implemented in the organization systems themselves and the implementation of "last mile" deliveries, aimed at increasing efficiency in fulfilling these tasks - i.e. the increase in the number of successfully completed delivery operations required by the market, while reducing the cost and delivery time of each individual delivery. The article is based on the analysis of the latest scientific and primary commercial studies devoted to this issue, supplemented with own conclusions and observations made by the author.

\section{Searching for modern equipment solutions}

Currently, transport and logistics entities - in order to be able to fully meet the requirements of their clients - must skillfully face challenges in various urban spaces. In their activities, they must therefore take into account the constantly growing individualization of production and trade, including the dispersion of delivery and collection points, and the increasing amount of goods in delivery with smaller shipments. In addition, there are many regulations and policies of numerous cities - mainly large agglomerations, aimed at eliminating vehicle traffic from centers. In addition, considerations should take into account the significant individualization of the environment, as external factors determining efficient and effective performance of tasks are different in every large city.

That is why recently entities that carry out transport within the so-called last mile logistics are increasingly reaching for innovative technological solutions ${ }^{1}$. They are to allow them to raise the level and method of customer service to an even higher level. The source of such creative solutions are, among others 'big data' collection, i.e. a huge amount of data available at hand, which can be a method to help suppliers improve the delivery process. In addition, there was a need to create adapted delivery places - urban logistics centers - in densely populated urban areas and/or around them. The answer to the dynamic growth of e-commerce is also the increased demand for logistic and warehouse space adjusted to the specificity

1 https://www.supplychaindive.com/news/last-mile-spotlight-trends-tech-gig-perfect/443091/ (access: 10.03.2018). 
of the industry. All these factors stimulate the development of the "last mile" sector and contribute to the development of the market of small storage modules cooperating with central warehouses. Thus, it comes to the creation of completely new supply systems based on changes in the distribution systems themselves and - in this context - changes in the structure and network of the existing storage system and the very concept of moving goods between individual components of the system. These changes cause not only the necessity to implement a different approach by logistic operators, but also direct transport companies that execute orders for them.

The goals of the changes made on the side of transport service include:

- acceleration of the processes carried out;

- physical offload of couriers at work - less effort will be required to perform specific tasks on their part;

- decrease of relative costs - in terms of shipment - of deliveries;

- reducing the number of people and equipment necessary to perform a given job - the removal of a specified number of shipments on a given day of work.

As a result, if only transport entities that perform tasks within the framework of logistic "last mile" delivery systems are taken into consideration, the higher and higher demands and challenges posed to them necessitate:

- appropriately oriented cost optimization;

- maintaining high flexibility, including demonstrating high innovation and the need for quick response to changes;

- creating - developing new business models;

- investing in new types of transport equipment.

In the sphere of equipment itself ${ }^{2}$, growing diversification is becoming more and more distinct. It manifests itself on the one hand with the appearance of new types of vehicles, on the other hand with the constantly increasing degree of taking over by existing vehicles the mobile functions of transport-handling-depot sub-stations. The result is the creation of transport hybrids: current light tonnage class vehicles - classic delivery trucks with a maximum authorized mass up to $6.000-7.500 \mathrm{~kg}$ and medium tonnage class trucks with a maximum authorized mass from $7.500-18.000 \mathrm{~kg}$, simultaneously perform two functions:

- as before, the means of transport from the receiving warehouse, but not as before - to the final recipient, but to a specific place near at least several places of final reception - locations of several recipients;

- a new function - performing the role of a base - a dock - depot for another mode of transport, which draws from them specific shipments to specified recipients and delivers them - in accordance with the given work algorithm - to these final recipients. This new means of transport in a mass system is a micro-mass - with a maximum mass from several dozen to a maximum of several hundred kilos, taking from several, several to several dozens, less often several hundred kilograms of cargo (up to 200-300 kg) and capable of autonomous, semi-autonomous or still classical move within a radius of several hundred meters to a maximum of a few

2 T. Schiller, M. Maier, M. Büchle, Global Truck Study 2016: The truck industry in transition, Deloitte, 2017, https://www2.deloitte.com/content/dam/Deloitte/us/Documents/manufacturing/us-manufacturing-global-truck-study-the-truck-industry-in-transition.pdf (access: 8.03.2018). 
kilometers from the dock-station. Such measures may include: self-propelled works - road drones, aerial drones, electric delivery vans and light delivery vans for final delivery operations.

Hence the marked dualization of their use and the hybridization of application. Other key processes are:

- autonomy of movement;

- limited or zero noise and harmful emissions. As a result, there must be an even stronger transition towards the use of alternative fuels and alternative drive units, the latter more and more often based solely on fully electric systems. Such systems ensure the required here: silent and zero emission of pollutants in connection with their other advantages - good accelerations, suited to the implementation of frequent start \& stop operations or the ability to recuperate and store the recovered electricity on board;

- increasing networking - networking.

In such circumstances, the existing delivery vehicle begins to act as a mobile base - a mobile dock for vehicles delivering on the last episode. It is therefore a vehicle directly responsible for delivery and logistics before the "last mile", while transported and/or transportable micro-carriers are already delivering as part of this "last mile". These micro-drives distinguish:

- high environmental performance - in practice, it only focuses on solutions with fully electric drive units that do not emit harmful substances and emit low noise levels;

- little occupied space - it is about 1 to $2-3 \mathrm{~m}^{2}$;

- moving - in the case of road vehicles - at low speed, usually not exceeding $10-15 \mathrm{~km} / \mathrm{h}$;

- preparation for semi-autonomous or fully autonomous movement, with compliance with all safety standards and standards in this respect;

- ability to operate in a network environment;

- ability to handle after a single load from one to at least several final recipients;

- use in the construction of many of the latest solutions, materials, technologies and software.

As a result, it should be assumed that the basic means of transport used until now ceases to be the only such measure on the last stretch of shipment of a given shipment - from the final magazine to the final recipient. In this model, it becomes a mobile subhab magazine, cooperating with other modes of transport, carrying out the movement at the very end, as part of the "last mile". These means may be taken by the basic means of transport taken together with shipments from the warehouse or may be waiting for it or used independently.

\section{Factors considered when introducing special means of transport for "last mile logistics"}

The key factors taken into account by carriers and operators and determining the advisability of using a special means of transport operated under the "last mile" systems are as follows: 
- purchase price;

- operating and service costs - full so-called total costs of ownership and disposal (TCO);

- absorbing people's work - the need for the operator to engage in ongoing service;

- energy efficiency;

- operational utility: the ability to perform a given job - carrying out specific transport tasks at a given time and - on this basis - the ability to effectively end up the work previously performed by people;

- protection of autonomous and semi-autonomous systems against unauthorized access;

- the possibility of effective implementation of tasks under specific road and weather conditions;

- additional equipment requirements for feeder transport - how extensive and deep modifications are necessary to introduce in previously used vehicles so that they can fully and effectively cooperate with special means of transport as part of last mile movements - i.e. can existing vehicles be used, existing vehicles after necessary modifications or it is necessary to introduce vehicles of other mass/tonnage categories with specially selected buildings.

These factors influence the decision to use, under certain conditions, with certain organizational, economic and operational constraints, the specific means of transport operated under the "last mile" systems.

\section{Basic advantages and disadvantages of new shipment measures implemented for use in last mile delivery systems}

From the equipment side, the most commonly considered, tested or even implemented equipment solutions are $^{3}$ :

- light and medium air drones;

- road drones - autonomous mobile robots - autonomous moving supply robots: intelligently in an automated way - managed vehicles, known in English as smart automated guided vehicles [AGV];

- special bicycles, electrically assisted bicycles and electric scooters. A representative of vehicles of this type is, for example, a new DHL City Hub bicycle, tested as part of the pilot program ${ }^{5}$;

3 https://fleetstreet.michelin-solutions.com/pl/2017/05/17/logistyka-na-ostatnim-kilometrze-koniec-pewnego-swiata/ (access: 7.03.2018).

4 http://www.inboundlogistics.com/cms/article/drones-in-last-mile-logistics-hype-or-help/; https:// www.supplychaindive.com/news/robots-drones-find-solution-for-the-last-mile-and-emergency-delivery/426951/ (access: 6.03.2018).

5 http://www.dpdhl.com/en/media_relations/specials/e-mobility.html; http://www.dpdhl.com/en/ media_relations/press_releases/2017/dhl_expands_green_urban_delivery_city_hub_cargo_bicycles. html (access: 7.03.2018). 
- special electric forklift trucks and other light vehicles with a maximum authorized weight up to $3.500 \mathrm{~kg}^{6}$. These vehicles can already be structurally prepared for fully autonomous movement ${ }^{7}$.

All of them are suitable for specific applications under certain conditions and according to the author, based on his research, show certain advantages and disadvantages (Table 1).

An unambiguous assessment of the presented special vehicles - transport solutions for deliveries under the so-called last mile logistics is therefore not possible. In fact, specific advantages and disadvantages can be seen very individually. Certain elements for some buyers, such as a higher price, may not be decisive, for others they will be a key barrier when making purchase decisions. Similarly, ambiguity in the assessment are issues related to ecology - for ecologically aware users in highly developed countries, this factor may play such an important role that they will be able to pay more for more expensive supplies with a more environmentally friendly fleet. At the same time, in poorer societies, the real inclination to pay more for ecology may be none or small. In addition, there are different labor costs in different countries - at high costs, the tendency to support or replace human work may be higher than at lower costs.

In addition, some of these types of vehicles require support in the form of another vehicle, fulfilling for them the role of a mobile - subhub. For drones, autonomous robots and possibly electrically assisted bicycles of such subhub can be a light-class delivery van, preferably a van with a permissible gross weight from 3.000 to $7.500 \mathrm{~kg}$. The electric delivery truck, however, already requires a heavier car, in the form of a tonnage class truck at least average, as in the French project BIL - Base Intelligente de Logistique by Libner ${ }^{8}$. Therefore, it can be assumed that the following requirements will appear for modifying the basic means of transport:

- drones - roof modifications, possible modifications in the building space;

- autonomous delivery works - modifications inside buildings;

- forklift trucks - a vehicle-carrier from a heavier mass category - medium instead of lightweight, in addition to a specially constructed structure for this purpose;

- electrically assisted bicycles, scooters - it is possible to leave previously used delivery vehicles, if only at certain points they will be reloaded on bicycles parcels or unified containers with parcels, or some modifications inside the body, if it serves as an exit base for these bikes.

As a result, the smallest alterations require the introduction of scooters and electrically assisted bicycles, the most and the most expensive, which are derived from the use of other car carriers with specially dedicated bodies - electric delivery trucks. Between these two categories, in the cost sphere, there are drones and mobile autonomous robots. In both cases, the costs of necessary changes and modifications, however, will not be exorbitant.

6 http://www.dpdhl.com/en/media_relations/press_releases/2017/dhl_ford_streetscooter_work_xl.htmldata; https://www.streetscooter.eu/, https://navya.tech/en, www.nysamotors.pl (access: 10.03.2018).

7 https://www.theverge.com/2018/1/8/16863092/toyota-e-palette-self-driving-car-ev-ces-2018; https:// www.toyota.ca/toyota/en/connect/2000/toyota-e-palette-concept-vehicle-ces-2018; http://www.dhl. com/content/dam/downloads/g0/about_us/logistics_insights/dhl_self_driving_vehicles.pdf (access: 7.03.2018).

8 http://bil.libner.com/bil/en (access: 22.02.2018). 
What's more, consider the subject of the universality of such specially selected bodies, i.e. how efficiently they will be able to continue to perform their tasks when they do not cooperate with special means of transport dedicated to relocate in the service of the "last mile". In this sphere, the situation is as follows:

- electrically assisted bicycles, electric scooters - the possibility of trouble-free and equally effective self-use;

- drones - the possibility of trouble-free and equally effective self-use;

- autonomous robots - the possibility of independent use with practically analogous efficiency - the space inside for works without major problems can be used as a normal cargo space for picked-up packages;

- forklifts - the possibility of independent use, but with the loss of a part of the cargo space, which in the situation does not take on board the trolley rather unlikely to be allocated to the cargo space. However, in newer solutions this option will probably appear - this space will be suitable for taking parcels, because it will be able to be equipped with a system of elastically selected attachment points for side shelves or locks in the floor and side covers in the form of a fixed door or sliding tarpaulin - a so-called curtain.

Additionally, in three cases - an electric delivery truck and an electric bicycle/bike and an electric scooter - vehicles must be driven by people. The organizational issue here concerns the issue of whether riding them will belong to the driver's duties a courier of a delivery vehicle - subhub, or - in an accepted distribution system of parcels - shipments will be packed with them from the main vehicle and will be distributed with them by a driver other than the operator car mobile subhub. In such a system, the most mobile, autonomous delivery robots can be the most effective. What's more, they can change the supply system very much. It can even be assumed that the evolution is rapidly changing towards their more massive use. These robots are used both at the level of the warehouses themselves and the delivery of last mile deliveries in order to reduce the requirements of the workforce and its costs, and help all parties involved in the chain to meet the increasing demand - the growing turnover created by the growth in e-commerce. To a large extent, they can affect how the last mile deliveries operate - perform operations of carriers, and even how access routes to warehouses, stores or residential houses are designed and built. These robots will ultimately be able to use, among others from driveways for cars or paths for wheelchairs and people with disabilities. In addition, in places, including blocks, where elevators for wheelchairs/wheelchairs are installed, in an intelligent - independent way they will be able to use them to carry out deliveries to higher floors.

Mobile robots are more flexible to use than traditional automated handling systems - handling shipments, as the latter require permanent infrastructure. Mobile robots/intelligent autonomous vehicles that they can carry or push as a pusher cargo to a specific location or function as intelligent, driverless trucks or lift trucks in warehouses, definitely reduce the need for labor not only at the level of the warehouses themselves or in within the distribution, but also allow for greater automation, easier installation and subsequent reconfiguration. 


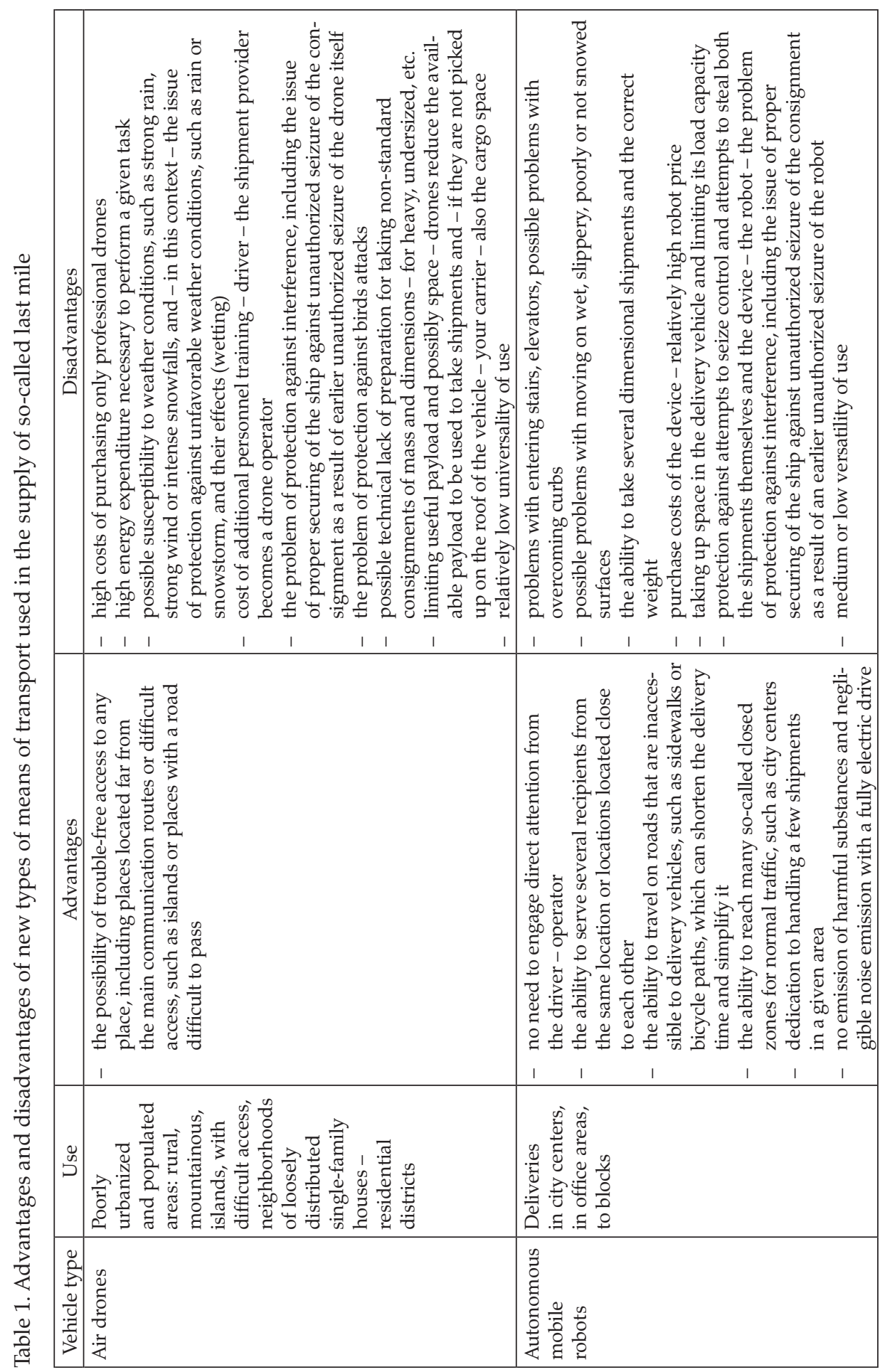




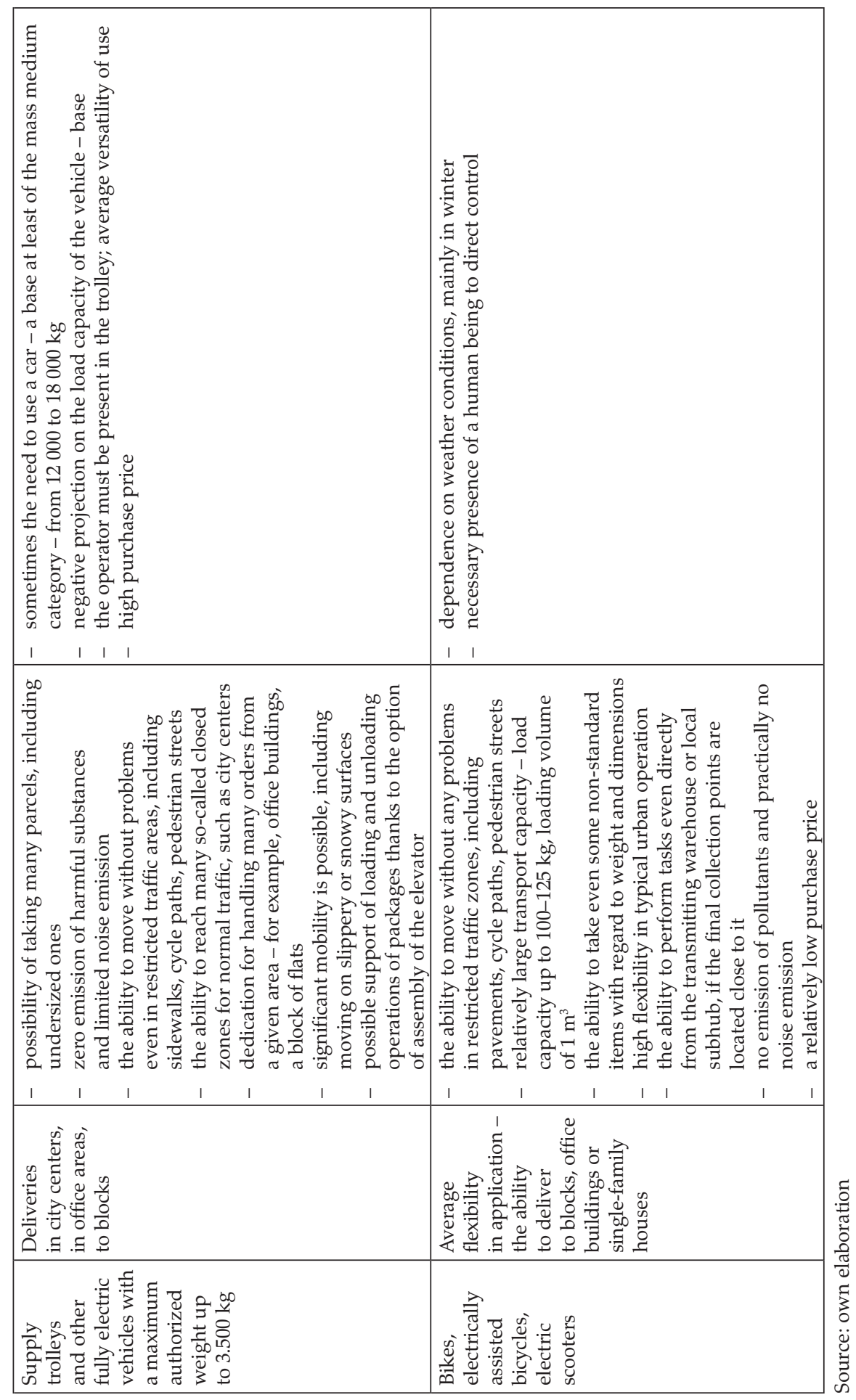


In the case of drones, the basic advantage of using them is a derivative of the fact that they prove to be helpful, faster, easier and cheaper to get to locations that are harder to access due to the road conditions - a difficult road, a target point located on an island, for example - and/or a drone it will defeat a much shorter route than a classic vehicle would have. Such a situation may occur in rural areas or generally poorly populated areas. At the same time, the driver of a car - a mobile subhub - a base for drones, when they are operated, is only absorbed in the control and control of these devices. As a result, he cannot deal with other activities. As a result, in such situations in the delivery of shipments, the act of driving a wheeled vehicle is replaced by the act of steering the drone. In the currently tested solutions autonomous drones do not work - drone capable of independent movement, due to the high degree of technical complexity of such studies and their fairly high price.

\section{The first results of research on the use of new means of relocation dedicated to deliveries under the "last mile"}

Made in the second half of 2016, the third research of the German ZF focused on "Last mile logistics". These tests were carried out by the Fraunhofer Institute for Flow of Materials and Logistics (IML) - these were so-called 360-degree examination of customer expectations, statutory and spatial framework conditions as well as technical trends and their effects. The published results indicated that delivery drones are likely to remain a niche solution, but in just a few years they will definitely gain autonomous significance of work. They will be able to perform tasks effectively - daily functions, both in large cities and in rural areas .

The first results of practical tests assessed as part of the Robotic Delivery Systems ${ }^{10}$ project also indicate the desirability and cost-effectiveness of implementing autonomous robots. The work is being carried out by the German Daimler concern Mercedes-Benz, cooperating with the Starship Technologies startup.

In the proposed solution, the lightweight delivery vehicle Sprinter acts as a mobile base station for delivery robots, acting as a mobile hub - a docking station. On the lower deck of the hold there is a "parking lot" for eight robots, on the upper so-called intelligent shelving with packages, and many processes are built-in automatically. Thanks to this, the courier's work becomes more efficient. In addition, the ICT system used continuously monitors the work and location of the robots to track where they are and where the vehicle should take them again. The robots themselves navigate the streets, sidewalks, streets and roads fully autonomously thanks to the combination of GPS navigation and multiple cameras. During autonomous driving, robots are able to overtake, avoid and overtake pedestrians and other obstacles encountered. Six-wheel robots type 6D63 are used here, without any problem overcoming even high curbs and safely that can use

\footnotetext{
9 https://press.zf.com/site/press/en_de/microsites/press/list/release/release_28033.html (access: 1.03.2018).

10 Roboty na ostatnim kilometrze. Jak uporać się z góra przesyłek w ekonomiczny i prosty sposób? Mercedes-Benz Vans wraz ze Starship Technologies już dziś testuja przyszłość, Mercedes Transporting 2017, 4, p. $22-33$.
} 
sidewalks. They can take up to 40 pounds $/ 18 \mathrm{~kg}$ of cargo and move autonomously at a foot speed within 3 miles $/ 5 \mathrm{~km}$ from the vehicle base - dock. They are powered fully electrically and consequently zero emission. During their journey, their cargo containers are closed - a specific container with a given shipment can only be opened by the appropriate recipient after receiving the unique individual code received earlier. Thanks to these robots, eight parcels can be delivered at the same time, which greatly increases efficiency. The tests already carried out proved that the courier-auto-delivery-work team during the 9-hour shift is able to deliver up to 400 items, compared to 180 delivered using the existing standard service method. The above means an increase by as much as $120 \%$. Functionally Sprinter and robots complement each other, as the robot's efficiency grows in connection with the car as a base. The system also provides support for the driver - he can do much more tasks in less time and he changes the nature of his work. He becomes a coordinator and a direct supervisor of robot work from the parcel carrier function.

In this context, the estimates of the consulting company McKinsey ${ }^{11}$ indicate that autonomous road drones - robots in the form of mobile parcel machines will replace the current forms of regular parcel deliveries. The above results from their cost advantage by $40 \%$ and more compared to today's conventional last-mile deliveries. This advantage becomes exceptionally clear not only in rural areas, but also urban - assuming that labor costs are around EUR 20 per hour. However, this cost advantage only exists if labor costs are higher than EUR 10-12 per hour. The $40 \%$ supply savings would translate into a $15 \%$ to $20 \%$ increase in profit margins or (more likely) - considering that in this market segment price is the key decision criterion, to a $15 \%$ to $20 \%$ reduction. In the industry with margins ranging between $2 \%$ and $5 \%$, these are significant values. In addition, as wages are likely to continue to rise, the advantage of autonomous forms of delivery will increase. At the same time, deliveries of the last mile to a much greater extent than at the moment will require the involvement of assets of significant value.

The test results with special urban reinforced bicycles are also very positive. The solution is successfully implemented, among others by the German DHL Express, which in selected countries in downtown operations replaced already $60 \%$ of vehicles with Cubicycle goods bicycles, supplemented by special City Hub trailers. Precisely, the company introduced bicycles in over 80 cities in 13 European countries, including 14 Cubicycles in seven cities. Courier Cubicycle cover an average of $50 \mathrm{~km}$ per day ${ }^{12}$.

Cubicycle was established in the Netherlands and DHL implemented it in 2015 in its network. It offers many features and benefits that make it ideal for express operations. It has removable standard containers, corresponding to the dimensions of the classic transport pallet. The total cost of ownership over the entire service life remains less than half of the maintenance costs of a lightweight distribution car.

${ }_{11}$ M. Joerss, J. Schröder, F. Neuhaus, C. Klink, F. Mann, Parcel delivery. The future of last mile, Travel, Transport and Logistics 2016, September, https://www.mckinsey.com/ /media/mckinsey/industries/ travel $\% 20$ transport $\% 20$ and $\% 20$ logistics/our $\% 20$ insights/how $\% 20$ customer $\% 20$ demands $\% 20$ are $\% 20$ reshaping\%20last\%20mile\%20delivery/parcel_delivery_the_future_of_last_mile.ashx (access: 1.03.2018).

12 http://www.dpdhl.com/en/media_relations/press_releases/2017/dhl_expands_green_urban_delivery_city_hub_cargo_bicycles.html (access: 9.03.2018). 
Equally important, it generates zero emissions, thus minimizing the negative impact on the environment and supports the efforts of municipal authorities to promote sustainable living in the city.

At this stage, such aided bikes are useful in this complex ecosystem, occurring instead of typical vans in heavily urbanized areas - densely populated, with difficult access.

In addition, despite some indications, some encouraging results are obtained with regard to drones. At the end of November $2017^{13}$, Mercedes-Benz completed a three-week test program at Zurich in Switzerland, which used its delivery trucks and drones. This program was carried out together with the American manufacturer of drones Matternet and the Swiss internet portal Siroop. Customers who ordered selected products for roasting coffee from a local company, on the same day received the opportunity to use the delivery with the help of a drone. Mercedes claims it has delivered 100 deliveries to 50 customers with a 100\% delivery rate, delivering packages up to 11 miles. At the same time, drones moved parcels not directly to the consumer, but to Mercedes vehicles in four pre-determined locations in the city. Then the packages were transported by van for a short distance to each address. The Vans and Drones program aims to shorten delivery time bypassing traffic in densely populated areas. His goal is to ultimately synchronize the drones and fleet of vans, so that the buyers do not have to drive to pre-established pick-up points, and pick up from vans on a regular route.

\section{Conclusions}

At present, the entire transport ecosystem must face new pressures and requirements from many sides. Most customers - buyers want more options, which results in a growing pressure on their wider and deeper individualization of service. It is because of the fact that a number of factors and phenomena in the environment support this. In this context, it is worth noting that: digitization create more opportunities and alternatives, in urban areas there are new delivery concepts, where destinations and recipients are concentrated - aggregated, resource sharing - assets change the meaning and the "ownership" account - ownership, and alternative types of vehicles can change the way in which time and work affect the financial result. At the same time, because goods will have to be physically moved further at individual stages, all changes implemented today relate to the cost-effectiveness, time and resources of this process, i.e. to make this movement relatively cheaper, faster and with reduced environmental footprints. At the same time, people have always tried to supplement or replace the work of animals and machines. For years, however, there were two major barriers to replace partially or completely the work of people. The most serious of these barriers included cost and technology factors. Now autonomous vehicles/robots begin to overcome this traditional trade-off between efficiency and flexibility, and the situation in this area is constantly

${ }^{13}$ http://www.automotive-fleet.com/channel/van/news/story/2017/11/mercedes-benz-considers-drone-test-program-a-success.aspx (access: 10.03.2018). 
improving due to improvements successively introduced in the robots themselves and as a derivative of the industry/sector gaining more and more experience related to their service.

Generally changes in delivery systems within the so-called last mile logistics are heading to the fact that these deliveries will take place through a dynamic network, what flexibility is based on performance and demand and depends on them. And in this scenario, the majority of innovations are implemented as part of the last mile. Companies, distribution centers and carriers physically moving parcels even over a distance of thousands of miles - they all have to implement a completely new approach. Particular importance will be given to it:

- extremely large individualization of the approach - adopted strategy in the area of used means of transport. There is no one perfect exit. Technologies must be selected on a case-by-case basis, with strong regard to the specificity of a given area, including its availability and/or recorded traffic volume, unique preferences of recipients, including their consent to pay for certain things, and cost and personal factors, including availability manpower, its costs and costs and benefits connected with its partial or total subsidence by modern technologies;

- flexibility in use - as the criterion adopted here refers to the possibility of full-time vehicles currently used in classical distribution as part of the "last mile logistics". These vehicles are light commercial vehicles, mostly mass category up to $7.500 \mathrm{~kg}$ permissible total weight.

What's more, any sensible potential means of delivery can be effectively used in this system. It can be not only drones and robots or special bikes, but also cyclists, walkers, individual drivers, taxis - that is everyone who is available at a given moment in a given area, to safely, reliably and on time deliver a package from point A to point B. As a result, even relatively low-tech advanced solutions can turn out to be extremely cost-effective, efficient and effective when the last mile deliveries issue. In addition, suppliers and resellers who can be at the center of this digital ecosystem are able to grow. At the same time, while many expect consolidation among players at the heart of the ecosystem, the total number of niche suppliers and informal part-time couriers is likely to grow steadily, at the very last moment effectively taking over market share.

\section{References}

http://www.automotive-fleet.com/channel/van/news/story/2017/11/mercedes-benz-considers-drone-test-program-a-success.aspx (access: 10.03.2018).

http://bil.libner.com/bil/en\#concept (access: 22.02.2018).

http://www.dailymail.co.uk/news/article-5144185/Is-Amazons-new-delivery-drone.html (access: 7.03.2018).

http://www.dpdhl.com/en/media_relations/specials/e-mobility.html (access: 10.03.2018). http://www.dpdhl.com/en/media_relations/press_releases/2017/dhl_expands_green_urban_ delivery_city_hub_cargo_bicycles.html (access: 9.03.2018).

http://www.dpdhl.com/en/media_relations/press_releases/2017/dhl_ford_streetscooter_ work_xl.html.

http://www.dhl.com/content/dam/downloads/g0/about_us/logistics_insights/dhl_self_driving_vehicles.pdf (access: 6.03.2018). 
https:/fleetstreet.michelin-solutions.com/pl/2017/05/17/logistyka-na-ostatnim-kilometrze-koniec-pewnego-swiata/ (access: 7.03.2018).

http://www.inboundlogistics.com/cms/article/drones-in-last-mile-logistics-hype-or-help/. https://navya.tech/en (access: 1.03.2018).

https://press.zf.com/site/press/en_de/microsites/press/list/release/release_28033.html (access: 1.03.2018).

https://www.streetscooter.eu/ (access: 1.03.2018).

https://www.supplychaindive.com/news/last-mile-spotlight-trends-tech-gig-perfect/443091/ (access: 10.03.2018).

https://www.supplychaindive.com/news/robots-drones-find-solution-for-the-last-mile-and-emergency-delivery/426951/.

https://www.toyota.ca/toyota/en/connect/2000/toyota-e-palette-concept-vehicle-ces-2018 (access: 7.03.2018).

https://www.udelv.com/ (access: 6.03.2018).

Joerss M., Schröder J., Neuhaus F., Klink C., Mann F., Parcel delivery. The future of last mile, Travel, Transport and Logistics 2016, September, https://www.mckinsey.com/ /media/ mckinsey/industries/travel\% 20transport\% 20and \% 20logistics/our\%20insights/how $\% 20$ customer $\% 20$ demands $\% 20$ are $\% 20$ reshaping $\% 20$ last $\% 20$ mile $\% 20$ delivery/parcel_delivery_the_future_of_last_mile.ashx (access: 1.03.2018).

Roboty na ostatnim kilometrze. Jak uporać się z góra przesyłek w ekonomiczny i prosty sposób? Mercedes-Benz Vans wraz ze Starship Technologies już dziś testuja przyszłość, Mercedes Transporting 2017, 4 .

Schiller T., Maier M., Büchle M., Global Truck Study 2016: The truck industry in transition, Deloitte, 2017, https://www2.deloitte.com/content/dam/Deloitte/us/Documents/manufacturing/us-manufacturing-global-truck-study-the-truck-industry-in-transition.pdf (access: 10.03.2018).

www.nysamotors.pl (access: 1.03.2018).

\section{Corresponding author}

Jarosław Brach can be contacted at: jaroslaw.brach@ue.wroc.pl 